\title{
Association Between Thyroid Function and Acute Exacerbation of Chronic Obstructive Pulmonary Disease
}

This article was published in the following Dove Press journal: International Journal of Chronic Obstructive Pulmonary Disease

\author{
Dan Huang \\ Dong Wu \\ Jinhong $\mathrm{He}$ \\ Min Chen \\ Xuanna Zhao \\ Dongming $\mathrm{Li}$ \\ Bin Wu (D)
}

Department of Respiratory and Critical Care Medicine, Affiliated Hospital of Guangdong Medical University, Zhanjiang, People's Republic of China
Correspondence: Dongming Li; Bin Wu Department of Respiratory and Critical Care Medicine, Affiliated Hospital of Guangdong Medical University, 57th South Renmin Road, Zhanjiang,

Guangdong, 52400I, People's Republic of China

Tel/Fax +8675923874I3

Email 1335887835@qq.com; wubin62I0II@I26.com
Purpose: Chronic obstructive pulmonary disease (COPD) was the fourth leading cause of death in the world. Many studies have shown that COPD often exists with thyroid dysfunction; however, the relationship between thyroid function and COPD is often ignored in clinical. We retrospectively analyze the serum thyroid hormone levels in patients with acute exacerbation of chronic obstructive pulmonary disease (AECOPD) and explore the association between thyroid function and AECOPD.

Methods: The study included patients hospitalized for AECOPD in our institution between January 2018 and September 2020. Patients with AECOPD were divided into moderate-tosevere and very severe groups based on lung function, and into normal and abnormal thyroid function groups based on thyroid hormone levels. Collected data and compared data between groups to identify risk factors for thyroid dysfunction in patients with AECOPD.

Results: The cohort included 97 in the moderate-to-severe group $(72.39 \%)$ and 37 in the very severe group $(27.61 \%)$. Compared with the very severe group, the moderate-to-severe group had higher triglyceride $(P=0.017)$, high-density lipoprotein $(P<0.05)$, partial pressure of carbon dioxide $\left(\mathrm{PaCO}_{2} ; P<0.05\right)$, and serum thyroid-stimulating hormone (TSH; $P<0.001) . \mathrm{FEV}_{1}$ as a percentage of the predicted value ( $\mathrm{FEV}_{1} \%$ pred) was positively correlated with TSH and $\mathrm{FT}_{3}(r=0.329, r=0.192$, respectively, both $P<0.05)$. Duration of hospitalization was negatively correlated with TSH $(r=-0.256, P=0.003)$. Among the 134 subjects, $98(73.13 \%)$ had normal thyroid function and $36(26.87 \%)$ had abnormal thyroid function. The two groups significantly differed regarding forced vital capacity (FVC), forced expiratory volume in 1 second, $\mathrm{FEV}_{1} \%$ pred, and albumin level. Logistic regression analysis showed that high FVC correlated with a low risk of thyroid dysfunction in AECOPD.

Conclusion: In patients with AECOPD, TSH is related to lung function and duration of hospitalization, and high FVC reduces the risk of thyroid dysfunction.

Keywords: AECOPD, thyroid hormone, retrospective cohort study, risk factor

\section{Introduction}

Chronic obstructive pulmonary disease (COPD) is a common, preventable, and treatable chronic airway inflammatory disease. COPD was the fourth leading cause of death in the world in 2019 and is predicted to be the third leading cause of death in 2020. ${ }^{1}$ In China, the estimated overall prevalence of COPD was $13.6 \%$ in 2014-2015, ${ }^{2}$ and COPD was the fifth leading cause of death in $2016 .^{3}$

COPD often exists with comorbidities that may significantly affect the disease course. Comorbidities not only affect symptom burden and health status but also affect the risk of hospitalization and mortality in patients with COPD. ${ }^{4}$ It is well 
known that the chronic inflammation of COPD is not just limited to the lungs, but spreads to other organs through the circulation. ${ }^{5}$ Comorbidities commonly recognized in patients with COPD include cardiovascular diseases, metabolic syndrome, osteoporosis, and anxiety. However, thyroid disease is also common in patients with COPD. ${ }^{6}$ A cross-sectional study from Spain showed that patients with COPD had a higher prevalence of thyroid disease $(14.2 \%)$ than the expected standardized prevalence of chronic diseases $(11.06 \%)$, and the prevalence of thyroid disease was higher in female than male patients $(24.6 \%$ vs $10.9 \%)^{7}$ Acute exacerbation of COPD (AECOPD) and the exacerbation frequency have negative effects on quality of life and survival. We recalculated Gumus A's study data and found a decrease in triiodothyronine $\left(\mathrm{T}_{3} ; 18.2 \%\right)$ and thyroid-stimulating hormone (TSH; 30.3\%) in patients with exacerbation of COPD ${ }^{8}$ furthermore, the exacerbation frequency was higher in patients with COPD with hypothyroidism than in those without hypothyroidism. The frequency of COPD exacerbation was positively correlated with TSH levels. ${ }^{9,10}$

The abovementioned findings suggest that the relationship between thyroid function and COPD may be underestimated. Therefore, we reviewed the clinical data of patients with AECOPD who had been admitted to our hospital in the past 2 years, analyzed the relationship between thyroid function and severity of illness in patients with AECOPD, and explored the related risk factors.

\section{Patients and Methods Study Population}

This was a retrospective cohort study. Data were collected from patients hospitalized for AECOPD in the Department of Respiratory and Critical Care Medicine, Affiliated Hospital of Guangdong Medical University between January 2018 and September 2020. Collected data included demographics, smoking history, diagnosis, treatment, duration of hospitalization, thyroid hormone levels, serum biochemical indexes, lung function, and arterial blood gas findings.

For all included patients, COPD was clinically diagnosed and confirmed by lung function testing, and hospitalization was initiated because of AECOPD. The diagnosis of COPD and classification of severity were based on the Global Initiative for Chronic Obstructive Lung Disease (GOLD) spirometry guidelines. AECOPD was defined as an acute worsening of respiratory symptoms that required additional therapy. Patients with AECOPD were divided in accordance with their lung function into a moderate-to-severe group (forced expiratory volume in 1 second as a percentage of the predicted value ( $\mathrm{FEV}_{1} \%$ pred) 30-79\%) and a very severe group $\left(\mathrm{FEV}_{1} \%\right.$ pred $\left.<30 \%\right)$. The inclusion criteria were: (1) age $\geq 40$ years; (2) moderate to very severe airflow limitation, post-bronchodilator $\mathrm{FEV}_{1}$ /forced vital capacity (FVC) ratio $<0.7$ and $\mathrm{FEV}_{1} \%$ pred $<0.8$; (3) detected serum thyroid hormone levels. The exclusion criteria were: (1) primary diagnosis of asthma; (2) severe bronchiectasis, pulmonary tuberculosis, or pulmonary fibrosis; (3) history of lung volume reduction surgery, pneumonectomy, or lung transplantation; (4) history of cancer; (5) history of thyroid disease, thyroid surgery, or administration of drugs containing iodine; (6) severe infection; (7) treatment administered before hospital admission.

Our study complied with the Declaration of Helsinki Ethical Principles for Medical Research Involving Human Subjects. As this was a retrospective study, informed consent of patient was not required by the Ethics Committee of Affiliated Hospital of Guangdong Medical University. The privacy of all participants was protected, we confirmed the data were anonymized and maintained with confidentiality.

\section{Statistical Methods}

SPSS statistical package (SPSS 22.0, IBM, USA) was used for all data analyses. The distributions of continuous variables were examined using the Kolmogorov-Smirnov normality test. Continuous variables with normal distribution were presented as mean \pm standard deviation, while continuous variables with non-normal distribution were presented as median and interquartile range (IQR). The chi-squared test was used to compare categorical variables between the moderate-to-severe group and the very severe group. Correlations among variables were analyzed using Spearman correlation test. Binary regression analyses were performed to evaluate the potential independent association between thyroid function and each of the assessed parameters. $P<0.05$ was considered statistically significant.

\section{Results}

\section{Patient Characteristics}

A total of 134 patients with AECOPD were included, including $97(72.39 \%)$ in the moderate-to-severe group and $37(27.61 \%)$ in the very severe group. The two groups 
did not differ regarding age, sex, BMI classification, smoking status and course of disease. Blood gas analysis showed a lower $\mathrm{PaCO}_{2}$ in the moderate-to-severe group than the very severe group $(43.30 \mathrm{mmHg}$ vs $47.80 \mathrm{mmHg}$; $P<0.001$ ), but no intergroup differences in $\mathrm{pH}$ and $\mathrm{PaO}_{2}$.

The serum triglyceride level was higher in the moderate-to -severe group than in the very severe group $(0.91 \mathrm{mmol} / \mathrm{L}$ vs $0.80 \mathrm{mmol} / \mathrm{L} ; P=0.017$ ), while the high-density lipoprotein level was lower in the very severe group than in the moderate-to-severe group $(1.37 \mathrm{mmol} / \mathrm{L}$ vs $1.54 \mathrm{mmol} / \mathrm{L}$, $P=0.025$ ). The other assessed biochemical indexes (albumin, calcium ion, creatinine, urea, uric acid, total cholesterol, and low-density lipoprotein) did not differ between the two groups. The TSH level significantly differed between the two groups $(P=0.001)$, but the $\mathrm{FT}_{3}$ and $\mathrm{FT}_{4}$ did not (Table 1, Supplemental Table 1)

\section{Correlations Between FEV $\%$ pred, $\mathrm{PaCO}_{2}, \mathrm{PaO}_{2}$, Duration of Hospitalization, and Thyroid Hormone Levels}

There were no correlations between the thyroid hormone levels and either $\mathrm{PaCO}_{2}$ or $\mathrm{PaO}_{2}$. However, TSH and $\mathrm{FT}_{3}$ were positively correlated with $\mathrm{FEV}_{1} \%$ pred $(r=0.329$ and $r=0.192$, respectively, both $P<0.05)$. The duration of hospitalization was negatively correlated with TSH $(r=-0.256$, $P=0.003$ ), but was not correlated with $\mathrm{FT}_{3}$ and $\mathrm{FT}_{4}$ (Table 2).

\section{Thyroid Hormone Levels in Patients with AECOPD}

We separated all patients into two groups in accordance with the serum thyroid hormone levels (normal ranges of serum $\mathrm{FT}_{3}, \mathrm{FT}_{4}$, and TSH: $2.3-6.8 \mathrm{pmol} / \mathrm{L}, 10-23.5 \mathrm{pmol} /$ $\mathrm{L}$, and $0.34-4.0 \mathrm{mIU} / \mathrm{L}$, respectively); the normal thyroid hormone group (normal group) comprised 98 patients $(73.13 \%)$ and the abnormal thyroid hormone group (abnormal group) comprised 36 (26.87\%). The two groups did not differ regarding age, sex, BMI classification, smoking status. The $\mathrm{FVC}, \mathrm{FEV}_{1}$, and $\mathrm{FEV}_{1}$ \%pred were higher in the normal group than the abnormal group (1.82 vs 1.38 , 0.91 vs 0.7 , and $42.72 \%$ vs $35.39 \%$, respectively, all $P<0.05)$. Blood gas analysis revealed that $\mathrm{pH}, \mathrm{PaO}_{2}$, and $\mathrm{PaCO}_{2}$ did not differ between the two groups. The serum albumin level was higher in the normal group than the abnormal group (39.15 g/L vs $37.47 \mathrm{~g} / \mathrm{L}, P=0.033$ ), but the other assessed biochemical indexes did not differ between the two groups (Table 3, Supplemental Table 2).

\section{Risk Factors for AECOPD Complicated with Abnormal Thyroid Function}

Table 4 shows that smoking history, FVC, $\mathrm{FEV}_{1}$, and $\mathrm{FEV}_{1} \%$ pred significantly differed between the normal and abnormal groups. We analyzed these data using binary regression analyses to identify the risk factors for abnormal thyroid function in patients with AECOPD. The FVC tended to be a protective factor to reduce the prevalence of abnormal thyroid function in patients with AECOPD (OR 0.114 , 95\% CI 0.015-0.887), while the other assessed variables showed no association with thyroid function.

\section{Discussion}

COPD is a respiratory disease that is prevalent worldwide and has chronic airway inflammation as is its major characteristic. In addition to airway inflammation, patients with COPD have inflammation in other body systems. The GOLD guidelines state that COPD is often complicated with many diseases, ${ }^{11}$ but thyroid dysfunction may be an underestimated complication of COPD due to insufficient clinical data. As we know, COPD patients often had a smoke history. Both cigarette smoke and chronic inflammatory in COPD itself can impair the thyroid gland, and lead to abnormal thyroid hormone production. ${ }^{12}$ Karadag et al demonstrated that the prevalence of non-thyroidal illness syndrome (abnormal thyroid hormone levels not due to thyroid disease) was $14-20 \%$ in patients with stable COPD, and $70 \%$ in patients with AECOPD. ${ }^{13}$ Of the 134 patients with AECOPD in the present study, approximately $26.87 \%$ had abnormal thyroid hormone levels. Due to the difference of AECOPD inclusion criteria between us, our data shown the prevalence of AECOPD with abnormal thyroid function was lower than in the study by Karadag et al. ${ }^{13}$ But our findings still suggest that thyroid dysfunction is common in patients with AECOPD.

Thyroid hormones play an important role in the regulation of metabolism by enhancing mitochondrial oxidation and augmenting the metabolic rate. ${ }^{14}$ The effect of thyroid hormones on the metabolic rate is probably responsible for the relationship between thyroid hormone levels and respiratory drive. ${ }^{15}$ Both hypothyroidism and hyperthyroidism can impair respiratory muscle function, respiratory mechanics, and exercise capacity in patients with COPD. ${ }^{16}$ Lung function (especially $\mathrm{FEV}_{1}$ \%pred) is used as the basis for grading COPD and is closely related to the severity of AECOPD. Siafakas et al showed that in patients with hyperthyroidism, inspiratory and expiratory muscle 
Table I Demographic and Clinical Characteristics of the Moderate-to-Severe Group Compared with the Very Severe Group

\begin{tabular}{|c|c|c|c|}
\hline Characteristics & $\begin{array}{c}\text { Moderate-to-Severe Group } \\
\qquad(\mathrm{n}=97)\end{array}$ & $\begin{array}{l}\text { Very Severe Group } \\
(n=37)\end{array}$ & $P$ value \\
\hline \multicolumn{4}{|l|}{ Demographic } \\
\hline Age years-old, Mean (SD) & $71.10(10.40)$ & $67.60(8.60)$ & 0.076 \\
\hline Male, Number (\%) & 68(70.1) & $3 I(83.8)$ & 0.127 \\
\hline Normal BMI kg/m², Median (IQR) ${ }^{\mathrm{a}}$ & $20.86(3.2)$ & $19.75(2.99)$ & 0.376 \\
\hline Low BMI kg/m², Median (IQR) ${ }^{\mathrm{b}}$ & $17.10(2.22)$ & $16.27(1.85)$ & 0.108 \\
\hline High BMI kg/m², Median $(\mathrm{IQR})^{\mathrm{c}}$ & $26.91(3.12)$ & $27.05(0)$ & 0.710 \\
\hline \multicolumn{4}{|l|}{ Clinical } \\
\hline Former smoker, Number (\%) & $25(25.8)$ & $14(48.3)$ & 0.203 \\
\hline Current smoker, Number (\%) & $25(25.8)$ & $15(40.5)$ & 0.138 \\
\hline Frequencies of AECOPD within one year $\geq 2$, Frequencies (\%) & $63(64.9)$ & $28(75.7)$ & 0.302 \\
\hline Course of disease-month, Median (IQR) & $96(84)$ & $120(60)$ & 0.656 \\
\hline \multicolumn{4}{|l|}{ Lung function tests } \\
\hline FVC-L, Median (IQR) & $\mathrm{I} .83(0.72)$ & $\mathrm{I} .47(0.4 \mathrm{I})$ & $<0.001$ \\
\hline $\mathrm{FEV}_{1}-\mathrm{L}$, Median (IQR) & $0.98(0.43)$ & $0.58(0.20)$ & $<0.001$ \\
\hline $\mathrm{FEV}_{1} \%$ pred, Median (IQR) & $47.65(11.99)$ & $23.63(4.56)$ & $<0.001$ \\
\hline \multicolumn{4}{|l|}{ Blood gas analysis } \\
\hline pH, Median (IQR) & $7.42(0.04)$ & $7.4 I(0.05)$ & 0.603 \\
\hline $\mathrm{PaO}_{2}-\mathrm{mmHg}$, Median (IQR) & $74.70(17.10)$ & $72.60(20.35)$ & 0.435 \\
\hline $\mathrm{PaCO}_{2}-\mathrm{mmHg}$, Median (IQR) & $43.30(7.30)$ & $47.80(8.30)$ & 0.001 \\
\hline \multicolumn{4}{|l|}{ Biochemical indexes $^{d}$} \\
\hline Albumin-g/L, Mean (SD) & $38.74(4.14)$ & $38.58(3.89)$ & 0.836 \\
\hline \multicolumn{4}{|l|}{ Thyroid hormone levels } \\
\hline $\mathrm{FT}_{3}$-pmol/L, Median (IQR) & $4.11(1.03)$ & $3.91(1.64)$ & 0.077 \\
\hline $\mathrm{FT}_{4-\mathrm{pmol} / \mathrm{L}, \text { Median (IQR) }}$ & $15.42(5.86)$ & $16.60(3.80)$ & 0.502 \\
\hline TSH-mIU/L, Median (IQR) & $1.05(1.16)$ & $0.54(0.64)$ & 0.001 \\
\hline
\end{tabular}

Notes: ${ }^{a}$ Normal BMI $\left(18.5-24.9 \mathrm{~kg} / \mathrm{m}^{2}\right)$; ${ }^{\mathrm{b}}$ Low BMI $\left(<18.5 \mathrm{~kg} / \mathrm{m}^{2}\right)$; ${ }^{\mathrm{C}}$ High BMI $\left(\geq 24.9 \mathrm{~kg} / \mathrm{m}^{2}\right)$; ${ }^{\mathrm{d}}$ Others of biochemical indexes see supplemental Table I.

Abbreviations: SD, standard deviation; BMI, body mass index; IQR, interquartile range (25th-75th percentile); AECOPD, acute exacerbation of chronic obstructive pulmonary disease; FVC, forced vital capacity; $\mathrm{FEV}_{1}$, forced expiratory volume in I second; $\mathrm{FEV}_{1} \%$ pred, $\mathrm{FEV}_{1}$ as a percentage of the predicted value; $\mathrm{FT}_{3}$, free triiodothyronine; $\mathrm{FT}_{4}$, free tetraiodothyronine; $\mathrm{TSH}$, thyroid-stimulating hormone; $\mathrm{pH}$, pondus hydrogenii; $\mathrm{PaCO}_{2}$, partial pressure of carbon dioxide; $\mathrm{PaO}$, partial pressure of oxygen.

weakness (expressed as a reduction in the $\mathrm{FEV}_{1}, \mathrm{FVC}$, in those with very severe AECOPD. Furthermore, the vital capacity, maximal expiratory pressure, and maximal inspiratory pressure) were positively correlated with the severity of hyperthyroidism; ${ }^{17}$ this was also supported by Terzano et al. ${ }^{18}$ Our results showed that the TSH level was higher in patients with moderate-to-severe AECOPD than $\mathrm{FVC}, \mathrm{FEV}_{1}$, and $\mathrm{FEV}_{1}$ \%pred were higher in patients with AECOPD with normal thyroid hormone levels than in those with abnormal thyroid hormone levels. We further analyzed the association between thyroid hormone levels and lung function and found that the $\mathrm{FEV}_{1} \%$ pred was

Table 2 Correlations Between $\mathrm{FEV}$ \%pred, $\mathrm{PaCO}_{2}, \mathrm{PaO}_{2}$, Duration of Hospitalization, and Thyroid Hormone Levels

\begin{tabular}{|l|c|c|c|c|c|c|c|c|}
\hline & \multicolumn{2}{|c|}{ FEV $\%$ pred } & \multicolumn{2}{c|}{ PaCO $_{2}$} & \multicolumn{2}{c|}{ PaO $_{2}$} & \multicolumn{2}{c|}{ Duration of Hospitalization } \\
\hline & $\boldsymbol{r}$ & $\boldsymbol{P}$ & $\boldsymbol{r}$ & $\boldsymbol{P}$ & $\boldsymbol{r}$ & $\boldsymbol{P}$ & $\boldsymbol{r}$ & $\boldsymbol{P}$ \\
\hline $\mathbf{F T}_{3}$ & 0.192 & 0.026 & 0.050 & 0.565 & 0.092 & 0.289 & -0.137 & 0.115 \\
$\mathbf{F T}_{\mathbf{4}}$ & -0.102 & 0.240 & -0.031 & 0.720 & 0.137 & 0.114 & 0.052 & 0.550 \\
$\mathbf{T S H}$ & 0.329 & $<0.001$ & -0.108 & 0.214 & 0.004 & 0.959 & -0.256 & 0.003 \\
\hline
\end{tabular}

Abbreviations: $\mathrm{PaCO}_{2}$, partial pressure of carbon dioxide; $\mathrm{PaO}_{2}$, partial pressure of oxygen; $\mathrm{FT}_{3}$, free triiodothyronine; $\mathrm{FT}_{4}$, free tetraiodothyronine; $\mathrm{TSH}$, thyroidstimulating hormone; $\mathrm{FEV}_{1} \%$ pred, forced expiratory volume in I second as a percentage of the predicted value. 
Table 3 Clinical Data of Patients with AECOPD with Normal and Abnormal Thyroid Hormone Levels

\begin{tabular}{|c|c|c|c|}
\hline Characteristics & $\begin{array}{l}\text { Normal Thyroid Hormone Group } \\
\qquad(n=98)\end{array}$ & $\begin{array}{l}\text { Abnormal Thyroid Hormone Group } \\
\qquad(n=36)\end{array}$ & $P$ value \\
\hline \multicolumn{4}{|l|}{ Demographic } \\
\hline Age years-old, Mean (SD) & $68.88(10.07)$ & $70.86(10.13)$ & 0.619 \\
\hline Male, Number $(\%)$ & $76(77.6)$ & $23(63.9)$ & 0.124 \\
\hline Normal BMI kg/m², Median (IQR) & $20.96(3.24)$ & $20.54(2.55)$ & 0.692 \\
\hline Low BMI kg/m², Median $(\mathrm{IQR})^{\mathrm{b}}$ & $16.97(1.69)$ & $16.33(2.79)$ & 0.412 \\
\hline High BMI kg/m², Median $(\mathrm{IQR})^{\mathrm{c}}$ & $26.91(3.06)$ & $27.05(4.91)$ & 0.947 \\
\hline \multicolumn{4}{|l|}{ Clinical } \\
\hline Former smoker, Number (\%) & $31(31.6)$ & $8(22.2)$ & 0.391 \\
\hline Current smoker, Number (\%) & $27(27.6)$ & $13(36.1)$ & 0.396 \\
\hline \multicolumn{4}{|l|}{ Lung function tests } \\
\hline FVC-L, Median (IQR) & $1.82(0.62)$ & $1.38(0.46)$ & $<0.001$ \\
\hline $\mathrm{FEV}_{1}$-L, Median (IQR) & $0.91(0.48)$ & $0.70(0.47)$ & $<0.001$ \\
\hline FEV,\%pred, Mean (SD) & $42.72(15.01)$ & $35.39(\mid 4.24)$ & 0.030 \\
\hline \multicolumn{4}{|l|}{ Blood gas analysis } \\
\hline $\mathrm{pH}$, Median (IQR) & $7.4 I(0.05)$ & $7.42(0.05)$ & 0.670 \\
\hline $\mathrm{PaO}_{2}-\mathrm{mmHg}$, Median (IQR) & 74.15(20.30) & $74.05(19.61)$ & 0.690 \\
\hline PaCO2-mmHg, Median (IQR) & $44.50(9.26)$ & $44.15(11.45)$ & 0.458 \\
\hline \multicolumn{4}{|l|}{ Biochemical indexes $^{d}$} \\
\hline Albumin-g/L, Mean (SD) & $39.15(4.00)$ & $37.47(4.01)$ & 0.033 \\
\hline
\end{tabular}

Notes: ${ }^{\mathrm{a}}$ Normal BMI $\left(18.5-24.9 \mathrm{~kg} / \mathrm{m}^{2}\right)$; ${ }^{\mathrm{b}}$ Low BMI $\left(<18.5 \mathrm{~kg} / \mathrm{m}^{2}\right)$; ${ }^{\mathrm{C} H i g h ~ B M I ~}\left(\geq 24.9 \mathrm{~kg} / \mathrm{m}^{2}\right)$; ${ }^{\mathrm{d}}$ Others of biochemical indexes see supplemental Table 2.

Abbreviations: AECOPD, acute exacerbation of chronic obstructive pulmonary disease; SD, standard deviation; BMI, body mass index; IQR, interquartile range (25th-75th

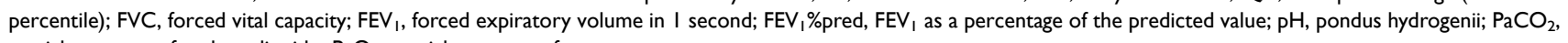
partial pressure of carbon dioxide; $\mathrm{PaO}_{2}$, partial pressure of oxygen.

positively correlated with the levels of $\mathrm{TSH}$ and $\mathrm{FT}_{3}$. These results demonstrated that the severity of airway obstruction was associated with the levels of TSH and $\mathrm{FT}_{3}$. These findings were consistent with Okutan $\mathrm{O}$ and Gao F's study. ${ }^{19,20}$ Ulasli et al found that TSH was the decisive factor in the frequency of AECOPD. ${ }^{9}$ In addition, Bacakoglu showed that low serum concentrations of $\mathrm{FT}_{3}$ and $\mathrm{FT}_{4}$ increased the incidence and mortality of invasive

Table 4 Risk Factors for AECOPD Complicated with Abnormal Thyroid Function

\begin{tabular}{|l|c|c|c|}
\hline Variables & OR & 95\% Cl & P value \\
\hline Smoking history & 0.754 & $0.295 \sim 1.929$ & 0.556 \\
FVC & 0.114 & $0.015 \sim 0.887$ & 0.038 \\
FEV $_{\text {I }}$ & 1.930 & $0.042 \sim 87.975$ & 0.736 \\
FEV \%pred & 0.990 & $0.943 \sim 1.040$ & 0.697 \\
Albumin & 0.929 & $0.831 \sim 1.038$ & 0.194 \\
\hline
\end{tabular}

Abbreviations: AECOPD, acute exacerbation of chronic obstructive pulmonary disease; OR, odds ratio; $\mathrm{Cl}$, confidence interval; FVC, forced vital capacity; $\mathrm{FEV}_{1}$, forced expiratory volume in I second; $\mathrm{FEV}_{1} \%$ pred, $\mathrm{FEV}_{1}$ as a percentage of the predicted value. mechanical ventilation in patients with respiratory failure. $^{21}$ These findings suggest that thyroid hormone levels probably influence the prognosis of AECOPD. Therefore, we analyzed the relationship between TSH and the duration of hospitalization and found that these factors were negatively correlated. We speculate that this is related to the lower severity of AECOPD in patients with higher TSH which is positively correlated to $\mathrm{FEV}_{1} \%$ pred. Furthermore, binary regression analysis revealed that the FVC was a protective factor to reduce the prevalence of thyroid dysfunction in patients with AECOPD.

The mechanism of thyroid dysfunction in COPD is not clear but may be related to hypoxemia and hypercapnia. ${ }^{21}$ Karadag et al found that TSH and $\mathrm{FT}_{3}$ were lower in patients with COPD with severe hypoxemia than in patients with milder hypoxia. ${ }^{13}$ In contrast, some studies demonstrated that thyroid hormones were not correlated with $\mathrm{pH}, \mathrm{PaO}_{2}$, or $\mathrm{PaCO}_{2} \cdot{ }^{22,23} \mathrm{We}$ also did not detect any relationship between TSH, $\mathrm{FT}_{3}, \mathrm{FT}_{4}$ and $\mathrm{PaO}_{2}$ or $\mathrm{PaCO}_{2}$. On the one hand, we speculate that this may be related to the fact that most of the 
patients included did not have respiratory failure; on the other hand, it may be related to the dynamic changes of hormones, $\mathrm{PaCO} 2, \mathrm{PaO} 2$ in the body, and dynamic observations may be better able to capture their correlations. Therefore, our team also plans to conduct prospective studies in order to provide more sufficient evidence for the relationship between thyroid hormones and AECOPD.

The results of the present study not only enhance the previous findings on the relationship between thyroid hormones and AECOPD but also add information that thyroid hormone levels influence the prognosis of AECOPD.

\section{Limitation}

As with all studies using retrospective information data, our study had some limitations. The clinical data that we could obtain from the medical record were limited. Therefore, we could not group subjects according to ABCD GOLD classification and perform more comprehensive comparisons between groups. Our findings were based on a single center and the sample size was limited, so the relationship between thyroid function and COPD maybe was underestimated or overestimated. Most stable COPD patients always inhaled hormones to control symptoms, we could not exclude it will affect the thyroid function. Although this study had some limitations, we hope these findings can raise clinical concerns about thyroid function in patients with COPD.

\section{Conclusion}

The clinical symptoms of thyroid dysfunction are often concealed by the symptoms of AECOPD, which leads to neglect and diagnostic difficulties. Our study shows that thyroid dysfunction is common in patients with AECOPD. Furthermore, serum TSH levels are positively correlated with the $\mathrm{FEV}_{1} \%$ pred and negatively correlated with the duration of hospitalization. These findings suggest that the thyroid function should be monitored in patients with AECOPD because this is related to patient recovery.

\section{Acknowledgments}

The authors would like to thank the staff of the Department of Respiratory and Critical Care Medicine, Affiliated Hospital of Guangdong Medical University for providing all the clinical data, and for their support and cooperation. We thank Kelly Zammit, BVSc, from Liwen Bianji, Edanz Editing China (www.liwenbianji.cn/ac), for editing the English text of a draft of this manuscript.

\section{Disclosure}

The authors of this study declare no conflicts of interest in this work.

\section{References}

1. Lopez-Campos JL, Soler-Cataluna JJ, Miravitlles M. Global strategy for the diagnosis, management, and prevention of chronic obstructive lung disease 2019 report: future challenges. Arch Bronconeumol. 2020;56(2):65-67. doi:10.1016/j.arbres.2019.06.001

2. Fang L, Gao P, Bao H, et al. Chronic obstructive pulmonary disease in China: a nationwide prevalence study. Lancet Respir Med. 2018;6(6):421-430.

3. Collaborators GBDCoD. Global, regional, and national age-sex specific mortality for 264 causes of death, 1980-2016: a systematic analysis for the Global Burden of Disease Study 2016. Lancet. 2017;390(10100):1151-1210.

4. Vanfleteren LE, Spruit MA, Groenen M, et al. Clusters of comorbidities based on validated objective measurements and systemic inflammation in patients with chronic obstructive pulmonary disease. $\mathrm{Am}$ J Respir Crit Care Med. 2013;187(7):728-735.

5. Barnes PJ, Celli BR. Systemic manifestations and comorbidities of COPD. Eur Respir J. 2009;33(5):1165-1185.

6. Milkowska-Dymanowska J, Bialas AJ, Zalewska-Janowska A, Gorski P, Piotrowski WJ. Underrecognized comorbidities of chronic obstructive pulmonary disease. Int J Chron Obstruct Pulmon Dis. 2015;10:1331-1341.

7. Garcia-Olmos L, Alberquilla A, Ayala V, et al. Comorbidity in patients with chronic obstructive pulmonary disease in family practice: a cross sectional study. BMC Fam Pract. 2013;14:11.

8. Gumus A, Ozyurt S, Ozcelik N, Kara BY. Prevalence of non-thyroidal illness syndrome in COPD exacerbation and effect of hypoxaemia and hypercapnia on thyroid functions. Clin Respir J. 2020;14(9):806-812.

9. Sarinc Ulasli S, Bozbas SS, Ozen ZE, Ozyurek BA, Ulubay G. Effect of thyroid function on COPD exacerbation frequency: a preliminary study. Multidiscip Respir Med. 2013;8(1):64.

10. Chaudhary SC, Ahmad T, Usman K, et al. Prevalence of thyroid dysfunction in chronic obstructive pulmonary disease patients in a tertiary care center in North India. J Family Med Prim Care. 2018;7(3):584-588. doi:10.4103/jfmpc.jfmpc_84_17

11. Disease GIfCOL. Global strategy for the diagnosis, management, and prevention of chronic obstructive pulmonary disease 2020 report. 2019. Available from: https://goldcopd.org/gold-reports/.

12. Milkowska-Dymanowska J, Bialas AJ, Laskowska P, Gorski P, Piotrowski WJ. Thyroid gland in chronic obstructive pulmonary disease. Adv Respir Med. 2017;85(1):28-34.

13. Karadag F, Ozcan H, Karul AB, Yilmaz M, Cildag O. Correlates of non-thyroidal illness syndrome in chronic obstructive pulmonary disease. Respir Med. 2007;101(7):1439-1446.

14. Silva JE. Thermogenesis and sympathoadrenal system in thyrotoxicosis. In: The Thyroid. A Fundamental and Clinical Text. 9. Braverman LE, Utiger RD, editors; 2005:607-620.

15. Saaresranta T, Polo O. Hormones and breathing. Chest. 2002;122 (6):2165-2182.

16. Laghi F, Adiguzel N, Tobin MJ. Endocrinological derangements in COPD. Eur Respir J. 2009;34(4):975-996.

17. Siafakas NM, Milona I, Salesiotou V, Filaditaki V, Tzanakis N, Bouros D. Respiratory muscle strength in hyperthyroidism before and after treatment. Am Rev Respir Dis. 1992;146(4):1025-1029.

18. Terzano C, Romani S, Paone G, Conti V, Oriolo F. COPD and thyroid dysfunctions. Lung. 2014;192(1):103-109.

19. Gao F. Correlation analysis of thyroid hormone levels and pulmonary function and nutritional status of patients with COPD in acute exacerbation. Zhejiang J Integr Trad Chin Western Med. 2017;27 (03):199-202. 
20. Bacakoglu F, Basoglu OK, Gurgun A, Bayraktar F, Kiran B, Ozhan MH. Can impairments of thyroid function test affect prognosis in patients with respiratory failure? Tuberk Toraks. 2007;55 (4):329-335.

21. Akpinar EE. An underestimated comorbidity of COPD: thyroid dysfunction. Tuberk Toraks. 2019;67(2):131-135.
22. Banks WA, Cooper JA. Hypoxia and hypercarbia of chronic lung disease: minimal effects on anterior pituitary function. South Med J. 1990;83(3):290-293.

23. Semple PD, Hume R, Beastall GH, Watson WS. Thyroid function and endocrine abnormalities in elderly patients with severe chronic obstructive lung disease. Thorax. 1988;43(11):945-946.

\section{Publish your work in this journal}

The International Journal of COPD is an international, peer-reviewed journal of therapeutics and pharmacology focusing on concise rapid reporting of clinical studies and reviews in COPD. Special focus is given to the pathophysiological processes underlying the disease, intervention programs, patient focused education, and self management protocols. This journal is indexed on PubMed Central, MedLine and CAS. The manuscript management system is completely online and includes a very quick and fair peer-review system, which is all easy to use. Visit http://www.dovepress.com/testimonials.php to read real quotes from published authors.

Submit your manuscript here: https://www.dovepress.com/international-journal-of-chronic-obstructive-pulmonary-disease-journal 